\title{
Time course of exhaled hydrogen peroxide and nitric oxide during chemotherapy
}

\author{
A.R. Wewel*, J.A.M. Crusius*, U. Gatzemeier*, M. Heckmayr*, G. Becher ${ }^{\#}$, \\ H. Magnussen*, R.A. Jörres ${ }^{\star, \oplus}$ and O. Holz*,+
}

ABSTRACT: This study was designed to assess the effect of differential leukocyte depletion during chemotherapy by monitoring the levels of exhaled hydrogen peroxide $\mathrm{H}_{2} \mathrm{O}_{2}$ and nitric oxide (FeNO) present.

In 39 patients with lung cancer (chronic obstructive pulmonary disorder up to stage II, median forced expiratory volume in one second $78 \%$ predicted), measurements were performed before a cycle of therapy (day 1 ), at least once during the cycle (day 8: $n=34$; day 15: $n=19$ ), and afterwards (days 21-29).

There were significant changes in the level of $\mathrm{H}_{2} \mathrm{O}_{2}, \mathrm{FeNO}$ and peripheral blood cell differentials over the visits. The level of $\mathrm{H}_{2} \mathrm{O}_{2}$ was decreased only on day 15, with a median (difference between the upper and lower quartiles) fall of 31 (57)\%, while FeNO was reduced only on day 8, by $22(40) \%$. Neutrophil numbers were unchanged on day 8 and decreased by $59(48) \%$ on day 15, while monocyte numbers were decreased on day 8 by $87(39) \%$. On days 21-29, values had returned to baseline.

Taken together with previous findings, the parallel course of levels of exhaled hydrogen peroxide and neutrophil counts suggests that a major part of exhaled hydrogen peroxide is due to neutrophils via the conducting airways. In contrast, the production of exhaled nitric oxide seems to be primarily associated with monocytes.

KEYWORDS: Carboplatin, cisplatin, exhaled breath condensate, neutrophils, peripheral blood

$\mathbf{H}$

ydrogen peroxide $\left(\mathrm{H}_{2} \mathrm{O}_{2}\right)$ in exhaled breath condensate (EBC) has been used over the last 15 yrs as a marker of airway inflammation [1]. Elevated levels of $\mathrm{H}_{2} \mathrm{O}_{2}$ were found in chronic obstructive pulmonary disease (COPD) [2-4], bronchiectasis [5], asthma [6-9], pneumonia [10] and cystic fibrosis [11], and these levels were responsive to anti-inflammatory [1214], antibiotic [11] or antioxidative interventions $[15,16]$. The flow dependence of $\mathrm{H}_{2} \mathrm{O}_{2}$ levels suggests that the conducting airways are the major site generating the exhaled $\mathrm{H}_{2} \mathrm{O}_{2}$ [17]. In addition, there are arguments that an important cellular source of exhaled $\mathrm{H}_{2} \mathrm{O}_{2}$ might be neutrophils, as suggested by the correlation with disease severity in COPD [2] or the findings in bronchiectasis [5]. However, inflammatory airway diseases are known to be associated with activation of various cell types. This introduces some difficulty in attributing the exhaled $\mathrm{H}_{2} \mathrm{O}_{2}$ to a specific cell type by correlation of baseline values in diseases of different severity. Similarly, antioxidative or anti-inflammatory interventions are likely to exert rather broad effects. In healthy subjects, more specific evidence on the cellular source of $\mathrm{H}_{2} \mathrm{O}_{2}$ has been provided by the correlation between baseline levels of $\mathrm{H}_{2} \mathrm{O}_{2}$ and the ability of blood neutrophils [18] or phagocytes [19] to become activated.

Based on this, ways to elicit effects on various cell types in a more selective or differential manner were explored. Furthermore, patients with no more than mild-to-moderate inflammatory airway disorders would probably show a more stable pattern of cellular activity over time than patients with severe disease, and a trial using an intervention and longitudinal analysis would keep patients' characteristics comparable between measurements. A major effect on leukocyte numbers is known to be elicited by chemotherapy, as used in the treatment of lung cancer. Various cell types are differentially affected, but the effect on neutrophils is by far the predominant one and can even reach the clinically significant state of neutropenia.

The present authors therefore measured exhaled $\mathrm{H}_{2} \mathrm{O}_{2}$ in patients undergoing chemotherapy for lung cancer to assess whether its level would change in parallel with neutrophil numbers in peripheral blood. Measurements were performed before, at least once during, and after a cycle of
AFFILIATIONS

*Hospital Großhansdorf, Center for Pneumology and Thoracic Surgery, Großhansdorf,

\#FILT, Berlin,

"Institute and Outpatient Clinic for Occupational and Environmental Medicine, Ludwig-Maximilians University, Munich, and +University of Lüneburg, Environmental Chemistry, Lüneburg, Germany.

CORRESPONDENCE

0 . Holz

Research Laboratory

Hospital Großhansdorf

Center for Pneumology and Thoracic Surgery

Wöhrendamm 80

D-22927 Großhansdorf

Germany

Fax: 494102692295

E-mail: 0.holz@pulmoresearch.de

Received:

September 012005

Accepted after revision:

December 232005

SUPPORT STATEMENT

This study was supported by Landesversicherungsanstalt (LVA) Freie und Hansestadt Hamburg, Germany. 
chemotherapy. For comparison, fractional exhaled nitric oxide $(F \mathrm{eNO})$ was also determined.

\section{SUBJECTS AND METHODS \\ Patients}

Thirty-nine participants without asthma and with COPD of, at most, stage II [20] were recruited from consecutive patients undergoing chemotherapy for lung cancer (table 1). Ten patients were Global Initiative for Chronic Obstructive Lung Disease (GOLD) stage 0, eight patients stage I, and 21 patients stage II (median (interquartile range)) forced expiratory volume in one second (FEV1) of this group: $72.3(5.3) \%$ predicted (\% pred); lowest value $59 \%$ pred). Three patients were atopic but did not have relevant allergen exposure. Five patients had small cell lung cancer, 33 had nonsmall cell lung cancer and one had mesothelioma. Tumour stages were Ia $(n=2)$, Ib $(n=1)$, IIIa $(n=2)$, IIIb $(n=11)$, IV $(n=21)$ and other $(n=2)$. The study was approved by the local ethics committee and patients gave their written informed consent.

\section{Study design}

Baseline data were obtained within $2 \mathrm{~h}$ before a cycle of chemotherapy (day 1). In 16 patients, this was the first cycle, in six the second, and in 17 a later cycle. Depending on their individual time schedule, patients visited the laboratory again on day 8 and/or day 15. To check whether values had returned to baseline, patients also visited the laboratory between day 21 and 29 (median 25) after chemotherapy. All measurements were performed in the morning within a time interval of $2 \mathrm{~h}$ to circumvent circadian variations.

Chemotherapy was based on carboplatin, cisplatin or other drugs in 24, 12 and three patients, respectively, and chosen independently from this study. Dexamethasone was given as antiemetic medication $\left(12 \mathrm{mg} \cdot \mathrm{day}^{-1}\right)$ over 1,3 or 5 days in one, two or 12 patients, respectively. Six patients received

\begin{tabular}{|c|c|c|}
\hline TABLE 1 & \multicolumn{2}{|c|}{$\begin{array}{l}\text { Patients' characteristics assessed upon } \\
\text { inclusion (day 1) }\end{array}$} \\
\hline \multicolumn{2}{|l|}{ Subjects $n$} & 39 \\
\hline \multicolumn{2}{|l|}{ Sex F/M } & $12 / 27$ \\
\hline \multicolumn{2}{|l|}{ Age yrs } & $64(12)$ \\
\hline \multicolumn{2}{|l|}{ Height $\mathrm{cm}$} & $173(9)$ \\
\hline \multicolumn{2}{|l|}{ BMI $\mathbf{k g} \cdot \mathrm{m}^{-2}$} & $26.0(8.4)$ \\
\hline \multicolumn{2}{|c|}{ FEV $1 \%$ pred } & $78.3(15.5)$ \\
\hline \multicolumn{2}{|c|}{ Smoking status ex-/current smoker } & $34 / 5$ \\
\hline \multicolumn{2}{|c|}{$\mathrm{COHb}$ in ex-smokers/smokers \% } & $1.0(0.7) / 5.0(2.6)$ \\
\hline \multicolumn{2}{|c|}{ Pack-yrs } & $40(29)$ \\
\hline \multicolumn{2}{|c|}{ Blood leukocyte count $\times 1000 \cdot \mu \mathrm{L}^{-1}$} & $7.14(3.45)$ \\
\hline \multicolumn{2}{|c|}{ Neutrophils $\%$} & $65(15)$ \\
\hline \multicolumn{2}{|c|}{ Lymphocytes \% } & $23(12)$ \\
\hline \multicolumn{2}{|c|}{ Monocytes \% } & $9(4)$ \\
\hline \multicolumn{2}{|c|}{ Eosinophils \% } & 2 (3) \\
\hline \multicolumn{2}{|c|}{ FeNO ppb } & $22.0(14.1)$ \\
\hline \multicolumn{2}{|l|}{$\mathrm{H}_{2} \mathrm{O}_{2} \mu \mathrm{M}$} & $0.49(0.37)$ \\
\hline
\end{tabular}

Data are presented as median (interquartile range), unless otherwise indicated. F: female; M: male; BMI: body mass index; FEV1: forced expiratory volume in one second; $\mathrm{COHb}$ : carboxyhaemoglobin; $F$ eNO: fractional exhaled nitric oxide. lenograstim (glycosylated granulocyte colony-stimulating factor, Granocyte ${ }_{\mathbb{R}}$; Chugai Pharma Europe Ltd, London, UK; dose 33.6 IU) after day 15 to counteract the fall in white blood cell numbers.

\section{Methods}

EBC was collected during $10 \mathrm{~min}$ of tidal breathing (ECoScreen; Viasys, Höchberg, Germany) while patients were wearing a nose-clip. The subjects were asked to remove the mouthpiece frequently and to swallow in order to avoid saliva accumulation in the mouth. After collection, the EBC was quickly thawed. $p$-Hydroxyphenylacetic acid (PHPA) and peroxidase were immediately added to a $300-\mu \mathrm{L}$ aliquot of EBC [17], which was mixed and then stored at $-20^{\circ} \mathrm{C}$. The reaction between $\mathrm{H}_{2} \mathrm{O}_{2}$ and PHPA forms a stable fluorescent product that can be stored for at least $1 \mathrm{yr}$. Standard solutions with known $\mathrm{H}_{2} \mathrm{O}_{2}$ concentrations were treated in the same way and were used to check the fluorometric measurements. The limit of detection was $0.03 \mu \mathrm{M}$. Blood differential cell counts (SF-3000; Sysmex, Hamburg, Germany) and FEV1 [21] were assessed by standard methods. FeNO was measured at a flow rate of $50 \mathrm{~mL} \cdot \mathrm{s}^{-1}$ [22] using a chemiluminescence analyser (NIOX; Aerocrine, Solna, Sweden). Ambient NO concentrations never exceeded $10 \mathrm{ppb}$.

\section{Data analysis}

Data are presented as median values (interquartile range). Comparisons of visits were performed using Friedmans' nonparametric ANOVA, pairwise comparisons by the Wilcoxon signed-rank test, and comparisons of groups by the MannWhitney U-test.

All patients $(n=39)$ were measured before the start of chemotherapy (day 1) as well as afterwards (days 21-29). As only 14 patients could attend both visits at day 8 and day 15 , two separate analyses were performed, comparing either day 8 with day 1 and days $21-29(n=34)$, or day 15 with day 1 and days 21-29 $(n=19)$ to keep the loss in statistical power small. As the groups having attended the laboratory on day 8 versus day 15 were comparable (table 2), and similar changes were found in the patients who had attended all visits, it was considered justified to pool all data for the purpose of illustration (fig. 1).

Variability was quantified by intraclass correlation coefficients via ANOVA. To facilitate a comparison with therapy-induced changes, it was additionally expressed as the absolute difference between the values observed at day 1 and days 21-29 relative to the mean of these values. Correlation analysis was performed by Spearman rank correlation. Statistical significance was assumed for $\mathrm{p}<0.05$.

\section{RESULTS}

\section{Changes in blood parameters}

When comparing days 1, 8 and 21-29, total leukocyte and neutrophil numbers showed no significant changes. In contrast, there was a difference in monocyte numbers (ANOVA, $\mathrm{p}<0.0001$ ), which were lowered at day 8 (table 2 ). The percentage of monocytes was reduced at day 8 , whereas that of neutrophils was raised ( $p<0.001$ each). 


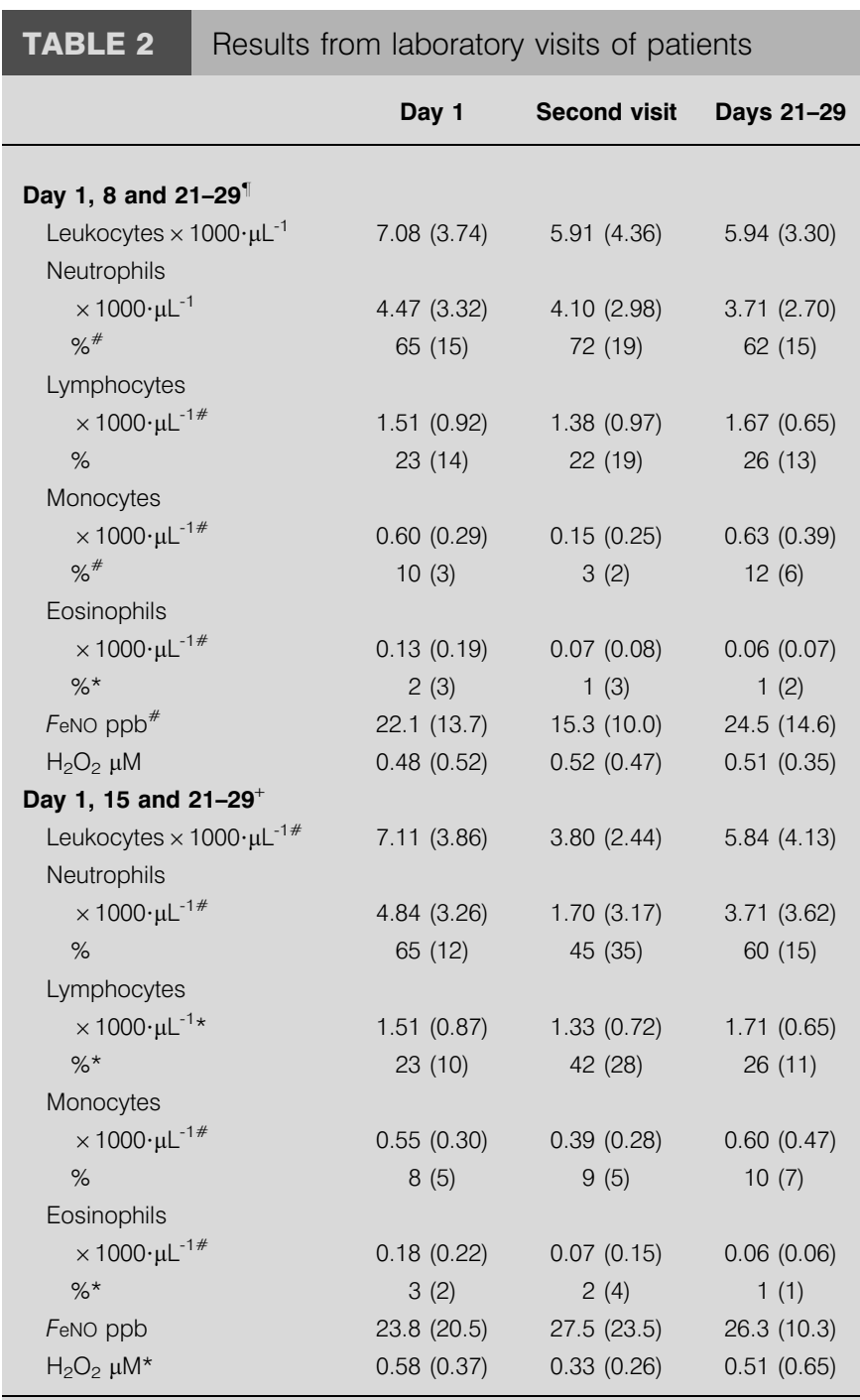

Data are presented as median (interquartile range). As only a minority of patients could be measured at day 8 as well as day 15 , the analysis was performed separately for the two groups having visited the laboratory at either day 8 or day $15{ }^{*}: p<0.05 ;{ }^{*}: p<0.005$ regarding the difference between visits (Friedmans' ANOVA) ${ }^{\bullet}: \mathrm{n}=34$.

When days 1, 15 and 21-29 were compared, there was a fall in leukocyte, neutrophil and monocyte numbers at day 15 (ANOVA, $\mathrm{p}<0.05$ each; table 2 ). The percentages of monocytes and neutrophils did not differ significantly between these three visits. Similarly to monocytes, changes in eosinophil and lymphocyte numbers occurred on both day 8 and day 15 (ANOVA, $\mathrm{p}<0.05$ each); the same was true for the percentage of eosinophils, which was lowered.

The median value (interquartile range) of the fall in leukocyte number on day 15 relative to day 1 was $2.38(3.04) \times 1,000 \cdot \mu \mathrm{L}^{-1}$ or $41(30) \%$. The neutrophil number was reduced by $1.78(2.72)$ $\times 1,000 \cdot \mu \mathrm{L}^{-1}$ or $59(48) \%$. Monocyte numbers were reduced by $0.42(0.31) \times 1,000 \cdot \mu \mathrm{L}^{-1}$ or $78(39) \%$ at day 8 and by $0.13(0.45)$ $\times 1,000 \cdot \mu \mathrm{L}^{-1}$ or $26(51) \%$ at day 15 , whereby changes were different between days $(\mathrm{p}<0.02$ each). The fall in eosinophil numbers was $0.04(0.09) \times 1,000 \cdot \mu \mathrm{L}^{-1}$ or $35(50) \%$ at day 8 , and
$0.07(0.23) \times 1,000 \cdot \mu \mathrm{L}^{-1}$ or $50(65) \%$ at day 15 . Corresponding reductions in lymphocyte numbers were $0.28(0.42) \times 1,000 \cdot \mu \mathrm{L}^{-1}$ or $21(27) \%$ and $0.31(0.64) \times 1,000 \cdot \mu \mathrm{L}^{-1}$ or $19(40) \%$.

When comparing days 1 and 21-29, only the absolute numbers of eosinophils (Wilcoxon, $\mathrm{p}<0.0001$ ) and the percentage of monocytes $(p=0.015)$ were significantly different. The fall in eosinophil numbers relative to day 1 was $0.05(14) \times 1,000 \cdot \mu \mathrm{L}^{-1}$ or $50(67) \%$.

The fall in leukocyte and neutrophil numbers at day 15 was also observed in the subgroups of patients who either had or had not received dexamethasone. It reached statistical significance in those without dexamethasone $(n=13 ; p<0.001$ each); only six patients receiving dexamethasone had been able to visit the laboratory at day 15 . The changes in monocyte, eosinophil and lymphocyte numbers over the four visits were also statistically significant in the group without dexamethasone $(\mathrm{p}<0.05$ each).

\section{Changes in exhaled $\mathrm{H}_{2} \mathrm{O}_{2}$}

When comparing days 1,8 and 21-29, there were no significant changes in the levels of $\mathrm{H}_{2} \mathrm{O}_{2}$. In contrast, there was a difference between days 1, 15 and 21-29 ( $\mathrm{p}=0.040$; ANOVA; table 2). The median (interquartile range) fall at day 15 was $0.18(0.39) \mu \mathrm{M}$ or $31.0(56.9) \%$. There was also a significant difference between days 1, 15 and 21-29 in the patients with COPD of stage II $(n=9)$ and in the group of the other patients $(p=0.05$ each). These two groups did not show a significant difference in baseline $\mathrm{H}_{2} \mathrm{O}_{2}$ levels at day 1 (0.46 (0.24) versus $0.70(0.59) \mu \mathrm{M})$.

\section{Changes in FeNO}

There was a significant difference in FeNO when comparing days 1,8 and 21-29 ( $\mathrm{p}=0.003)$, but not when comparing days 1 , 15 and 21-29 (table 2). Compared with day 1, the level of FeNO was reduced by $3.8(10.8) \mathrm{ppb}$ or $22.3(40.2) \%$ at day 8 . This fall was also observed in the two subgroups who had $(n=20$, $\mathrm{p}=0.015)$ or had not $(\mathrm{n}=14, \mathrm{p}=0.037)$ received dexamethasone, as well as in the subgroup with COPD of stage II $(n=17$, $\mathrm{p}=0.0014$ ), but not in the other patients.

\section{Variability and correlations}

The variables not showing statistically significant differences between days 1 and 21-29 were used to obtain upper limit estimates of variability over the time of the study. Median (interquartile range) values of variability of leukocyte, neutrophil, monocyte and lymphocyte counts, $\mathrm{Fe}, \mathrm{NO}$ and exhaled $\mathrm{H}_{2} \mathrm{O}_{2}$ were 25 (29), $31(30), 29$ (38), 12 (20), 24 (39) and $53(86) \%$, respectively. Corresponding intraclass correlation coefficients were $0.81,0.75,0.68,0.77,0.60$ and 0.12 .

There were no statistically significant correlations between individual changes of neutrophil numbers and $\mathrm{H}_{2} \mathrm{O}_{2}$ levels, or monocyte numbers and FeNO levels. The same was true for leukocyte, eosinophil or lymphocyte numbers, as well as baseline FEV1.

\section{DISCUSSION}

The present data indicate that during chemotherapy for lung cancer, the level of $\mathrm{H}_{2} \mathrm{O}_{2}$ in EBC decreased in parallel with peripheral blood neutrophil numbers. There was also a fall in the FeNO. This fall occurred prior to the fall in neutrophil 

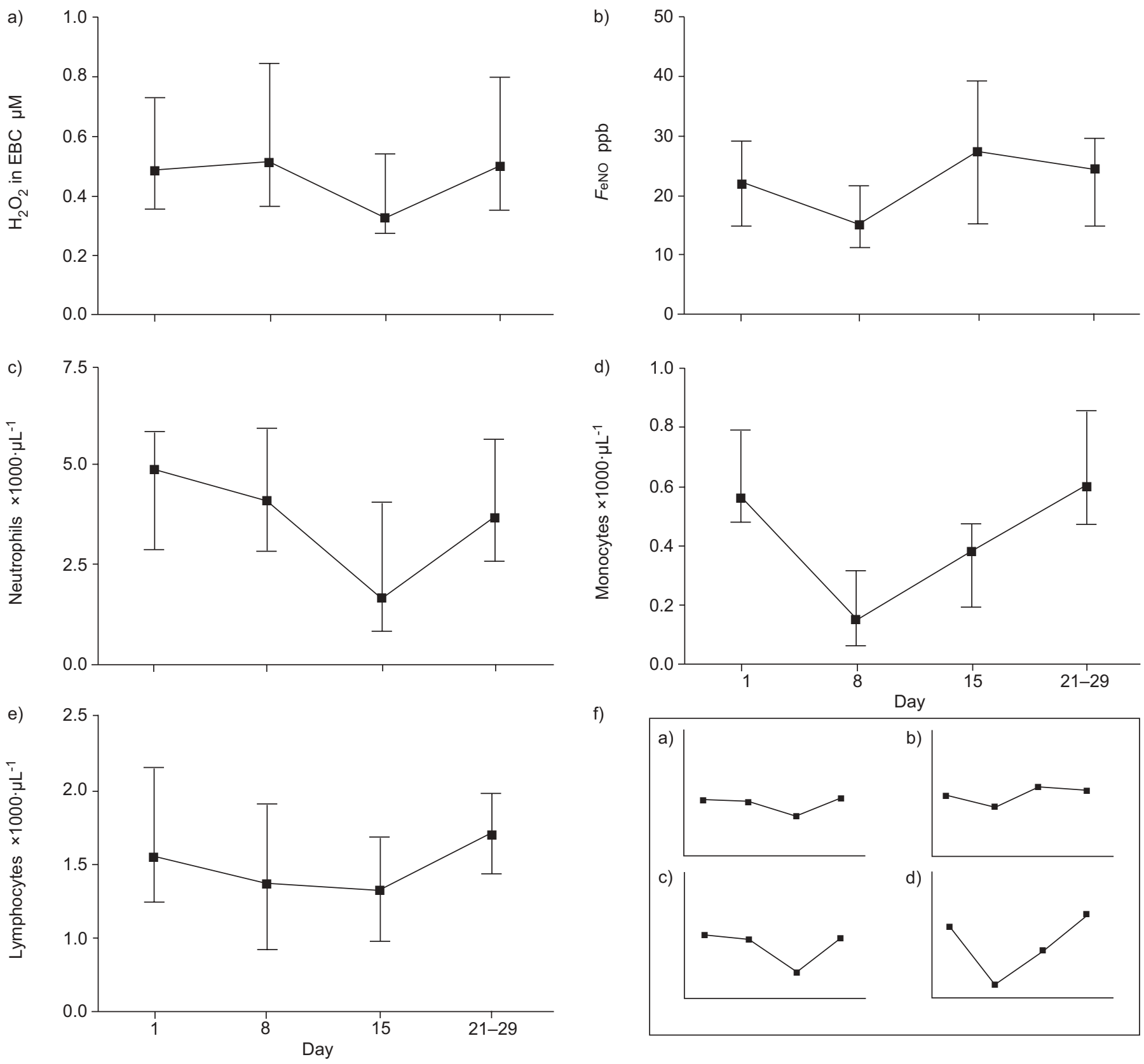

FIGURE 1. Time course of the concentration of hydrogen peroxide $\left(\mathrm{H}_{2} \mathrm{O}_{2}\right)$ in a) exhaled breath condensate $(\mathrm{EBC})$ and b) the fraction of exhaled nitric oxide (FeNO), and the number of $\mathrm{c}$ ) neutrophils, d) monocytes and e) lymphocytes in peripheral blood. The horizontal axis represents the four consecutive visits. Median values and interquartile ranges are shown. For eosinophils, see table 2. To increase the reliability of statistical parameters, the graphs comprise all available data and therefore represent different groups of patients at day 1 and days 21-29 $(n=39)$ versus day $8(n=34)$ versus day $15(n=19)$. As the values in these groups were very similar (see table 2), we compiled the data in this way for the purpose of data visualisation. f) illustrates that the pooling was not misleading. It depicts median values of $\mathrm{H}_{2} \mathrm{O}_{2}$ (a), FeNO (b), neutrophils (c) and monocytes (d) in those 14 patients who attended all four visits; scales are the same as in a-e.

numbers and $\mathrm{H}_{2} \mathrm{O}_{2}$ levels, at a time when monocyte numbers in peripheral blood were markedly reduced.

The parallel time course of neutrophil numbers and $\mathrm{H}_{2} \mathrm{O}_{2}$ concentration, and the discordant course of monocyte, eosinophil and lymphocyte numbers (fig. 1) favour the conclusion that neutrophils were the major source of exhaled $\mathrm{H}_{2} \mathrm{O}_{2}$, or at least closely associated with its generation. Conversely, the simultaneous fall of FeNO levels and monocyte numbers suggests monocytes (or macrophages) are basically involved in the production of exhaled NO. It might even be that the recovery of FeNO levels at day 15, when monocyte numbers were still lowered, was linked to the fall in $\mathrm{H}_{2} \mathrm{O}_{2}$ level at this time point.

Indeed, a reduction in superoxide production by inhibition of xanthine oxidase was found to be associated with a rise in the level of FeNO [23]. An interaction between reactive oxygen 
species (ROS) and NO is further suggested by the inverse relationship between the levels of exhaled $\mathrm{H}_{2} \mathrm{O}_{2}$ and atmospheric inhaled NO [24]. Thus, NO production might have been reduced on both day 15 and day 8, but a reduced ROS production allowed more NO to evade into the airway lumen. The fact that $F$ eNO variation was largest at day 15 also appears to be in favour of this explanation. These effects were transient, as FeNO and $\mathrm{H}_{2} \mathrm{O}_{2}$ values were back to baseline at days 21-29. The fall in FeNO could also not be explained by dexamethasone, which had been administered in some patients after infusion.

Within the setting of the current study, FeNO was primarily considered as an indicator of scavenging or of potential alterations in the transfer from airway mucosa to lumen. Such alterations could affect the level of exhaled $\mathrm{H}_{2} \mathrm{O}_{2}$ in the absence of changes in production. When $\mathrm{H}_{2} \mathrm{O}_{2}$ level decreased at day 15, there was no change in $\mathrm{FeNO}$, at least on average. If this was the consequence of less NO being scavenged by ROS, questioning FeNO as indicator of unaltered transfer, the argument still requires a reduction of ROS production, in accordance with the fall in $\mathrm{H}_{2} \mathrm{O}_{2}$ level. Taken together with previous evidence that the exhaled $\mathrm{H}_{2} \mathrm{O}_{2}$ originates primarily in the airways [17], i.e. the site where the exhaled $\mathrm{NO}$ also originates, the present data thus suggest that the fall in $\mathrm{H}_{2} \mathrm{O}_{2}$ level at day 15 did indeed represent a decrease of $\mathrm{H}_{2} \mathrm{O}_{2}$ production.

Utilising a massive intervention, such as chemotherapy, to study the different effects on different cell types rendered it less difficult to attribute exhaled $\mathrm{H}_{2} \mathrm{O}_{2}$ to a specific cell type than comparing patients with marked airway disease would have done. As lenograstim was administered following day 15, it did not affect the effects observed at days 8 and 15 . The analysis of the time course of cell differentials confirmed that neutrophils were most affected by chemotherapy. Monocyte, lymphocyte and eosinophil counts also showed reductions, which occurred on both day 8 and day 15, and eosinophil numbers stayed low until days 21-29. These patterns were discordant to the course of $\mathrm{H}_{2} \mathrm{O}_{2}$ (fig. 1), whereas FeNO levels fitted closest to monocytes.

As it is known that bronchoalveolar lavage fluid taken from the tumour site contains an elevated number of neutrophils [25], the presence of a tumour might have affected $\mathrm{H}_{2} \mathrm{O}_{2}$ levels. However, baseline $\mathrm{H}_{2} \mathrm{O}_{2}$ levels of patients (table 1) were not significantly different from those obtained in healthy control subjects measured during the study period (data not shown). There was also no correlation between tumour stage or type and $\mathrm{H}_{2} \mathrm{O}_{2}$ level. It is therefore unlikely that local effects, which might be assumed to be particularly sensitive to chemotherapy, have affected the results of this study.

Data obtained in healthy subjects have demonstrated correlations of $\mathrm{H}_{2} \mathrm{O}_{2}$ levels with the ability of blood phagocytes or neutrophils to be activated [18, 19], thus indicating the suitability of blood parameters. These studies did not include FeNO measurements, neither did they use an intervention to elicit changes in cell numbers. Neutrophils are known to be abundant in the conducting airways and, given their short lifetime, similar changes in peripheral blood and airways might be expected. In a previous study, however, there was no significant fall in sputum neutrophil counts 21 days after chemotherapy, despite a fall in blood neutrophils [26]. Due to restrictions imposed by the patients' therapy schedules, it was not possible to include sputum induction in the present study. The difference might have been due to the variability of sputum cell counts, and the difficulty in drawing conclusions on airway cell numbers from sputum cell density, as well as the timing of measurements. In the present study, measurements were made earlier, close to the expected minimum of cell counts, and patients had less severe airway disease, thus reducing the likelihood for stable disease-related airway neutrophilia. In addition, chemotherapy has probably affected both cell number and activation, and the data regarding blood phagocytes $[18,19]$ indicate that activation can play a role for exhaled $\mathrm{H}_{2} \mathrm{O}_{2}$.

Indeed, using superoxide production as an indicator, a reduction of the neutrophils' ability to produce ROS has been demonstrated for a broad spectrum of chemotherapeutic agents [27]. In addition, the platinum compounds used in chemotherapy might have lowered superoxide dismutase activity, as demonstrated in cochlear or renal cells [28], resulting in lower $\mathrm{H}_{2} \mathrm{O}_{2}$ production. Conversely, the simultaneous reduction of catalase activity would have reduced $\mathrm{H}_{2} \mathrm{O}_{2}$ removal. In contrast to neutrophils, ROS release by macrophages can be enhanced by platinum compounds [29]. Thus, chemotherapy might have influenced exhaled $\mathrm{H}_{2} \mathrm{O}_{2}$ via ROS production of phagocytes and antioxidant enzyme activities, but the overall effect of these factors in the setting used by the present authors is difficult to estimate. Most importantly, these effects have a rapid onset, in contrast to the delayed $\mathrm{H}_{2} \mathrm{O}_{2}$ response observed in the present study.

NO appears to play a role in carcinogenesis and tumour growth via an interplay between reactive nitrogen species and ROS, whereby chemotherapeutic agents exert multiple effects, such as an increase of inducible NO production [30] versus NOmediated apoptosis [31] in macrophages. Compared with a threshold value of 20 (35) ppb, 24 (7) of the 39 patients showed an elevated level of $\mathrm{FeNO}$, although patients with asthma had been excluded. There was no relationship between $\mathrm{FeNO}$ and infections which occurred in six patients, although the highest $\mathrm{FeNO}$ value was found in a patient with infection. In addition, blood eosinophils and FeNO were not correlated with each other.

Most patients were ex-smokers who had stopped smoking several weeks before therapy. Smoking is known to lead to a reduction of $F$ eNO levels, probably due to scavenging by ROS. After smoking cessation, FeNO levels rise over $\sim 1-4$ weeks [32]. The time of the start of the study, as well as the fall in FeNO level at day 8, did not favour the assumption that smoking cessation has biased $\mathrm{FeNO}$ measurements. A similar reasoning applies to $\mathrm{H}_{2} \mathrm{O}_{2}$. Smokers without major airway disease show elevated levels of antioxidants and antioxidant enzyme activity in bronchoalveolar lavage fluid [33], but there are no data regarding smoking cessation. Theoretically, a fall in antioxidant levels should have led to an increase in the $\mathrm{H}_{2} \mathrm{O}_{2}$ level, not a decrease as observed. Direct measurements of exhaled $\mathrm{H}_{2} \mathrm{O}_{2}$ also did not provide evidence that smoking had an effect on $\mathrm{H}_{2} \mathrm{O}_{2}$ in mild COPD [3]. Thus, it is likely that smoking cessation had no impact on the present findings. 
The fact that there was no correlation between individual changes of neutrophil numbers and $\mathrm{H}_{2} \mathrm{O}_{2}$ levels was probably due to the large variability of $\mathrm{H}_{2} \mathrm{O}_{2}$ measurements, which is known from previous studies [17, 34, 35]. As the intervention might have increased variability, coefficients of variation derived by comparing days 1 and 21-29 have to be viewed as upper bounds. Variability of $\mathrm{H}_{2} \mathrm{O}_{2}$ was greater than that of other variables, its median value being $>50 \%$ and nearly twice the magnitude of the fall observed at day 15.

In conclusion, the present data demonstrated a parallel course between the level of exhaled hydrogen peroxide and blood neutrophil counts during chemotherapy. The course of fractional exhaled nitric oxide was different, and was most similar to that of monocyte numbers. On the basis of previous data indicating that the exhaled hydrogen peroxide originates mainly in the bronchi, the present findings suggest that hydrogen peroxide in exhaled breath condensate is primarily a marker of neutrophil number and/or activation, which is detectable via and probably located in the conducting airways.

\section{ACKNOWLEDGEMENTS}

The authors would like to thank all patients for their kind cooperation. They are also grateful to K. Paasch and I. Schwertfeger for technical support, and to A. Bergner, LMU Munich, Germany, for valuable comments.

\section{REFERENCES}

1 van Beurden WJ, Dekhuijzen PN. Hydrogen peroxide in exhaled breath condensate. In: Paolo Montusci, ed. New Perspectives in Monitoring Lung Inflammation. Analysis of Exhaled Breath Condensate. Boca Raton, London, New York, Washington DC, CRC Press, 2005; pp. 67-72.

2 Dekhuijzen PN, Aben KK, Dekker I, et al. Increased exhalation of hydrogen peroxide in patients with stable and unstable chronic obstructive pulmonary disease. Am J Respir Crit Care Med 1996; 154: 813-816.

3 Nowak D, Kasielski M, Antczak A, Pietras T, Bialasiewicz P. Increased content of thiobarbituric acidreactive substances and hydrogen peroxide in the expired breath condensate of patients with stable chronic obstructive pulmonary disease: no significant effect of cigarette smoking. Respir Med 1999; 93: 389-396.

4 De Benedetto F, Aceto A, Dragani B, et al. Validation of a new technique to assess exhaled hydrogen peroxide: results from normals and COPD patients. Monaldi Arch Chest Dis 2000; 55: 185-188.

5 Loukides S, Bouros D, Papatheodorou G, Lachanis S, Panagou P, Siafakas NM. Exhaled $\mathrm{H}(2) \mathrm{O}(2)$ in steady-state bronchiectasis: relationship with cellular composition in induced sputum, spirometry, and extent and severity of disease. Chest 2002; 121: 81-87.

6 Antczak A, Nowak D, Shariati B, Krol M, Piasecka G, Kurmanowska Z. Increased hydrogen peroxide and thiobarbituric acid-reactive products in expired breath condensate of asthmatic patients. Eur Respir J 1997; 10: 1235-1241.

7 Jöbsis Q, Raatgeep HC, Hermans PW, de Jongste JC. Hydrogen peroxide in exhaled air is increased in stable asthmatic children. Eur Respir J 1997; 10: 519-521.
8 Horvath I, Donnelly LE, Kiss A, et al. Combined use of exhaled hydrogen peroxide and nitric oxide in monitoring asthma. Am J Respir Crit Care Med 1998; 158: 1042-1046.

9 Emelyanov A, Fedoseev G, Abulimity A, et al. Elevated concentrations of exhaled hydrogen peroxide in asthmatic patients. Chest 2001; 120: 1136-1139.

10 Majewska E, Kasielski M, Luczynski R, Bartosz G, Bialasiewicz P, Nowak D. Elevated exhalation of hydrogen peroxide and thiobarbituric acid reactive substances in patients with community acquired pneumonia. Respir Med 2004; 98: 669-676.

11 Jöbsis Q, Raatgeep HC, Schellekens SL, Kroesbergen A, Hop WC, de Jongste JC. Hydrogen peroxide and nitric oxide in exhaled air of children with cystic fibrosis during antibiotic treatment. Eur Respir J 2000; 16: 95-100.

12 Antczak A, Kurmanowska Z, Kasielski M, Nowak D. Inhaled glucocorticosteroids decrease hydrogen peroxide level in expired air condensate in asthmatic patients. Respir Med 2000; 94: 416-421.

13 Emelyanov A, Fedoseev G, Krasnoschekova O, Abulimity A, Trendeleva T, Barnes PJ. Treatment of asthma with lipid extract of New Zealand green-lipped mussel: a randomised clinical trial. Eur Respir J 2002; 20: 596-600.

14 van Beurden WJ, Harff GA, Dekhuijzen PN, van der PoelSmet SM, Smeenk FW. Effects of inhaled corticosteroids with different lung deposition on exhaled hydrogen peroxide in stable COPD patients. Respiration 2003; 70: 242-248.

15 Kasielski M, Nowak D. Long-term administration of $\mathrm{N}$ acetylcysteine decreases hydrogen peroxide exhalation in subjects with chronic obstructive pulmonary disease. Respir Med 2001; 95: 448-456.

16 De Benedetto F, Aceto A, Dragani B, et al. Long-term oral $\mathrm{N}$-acetylcysteine reduces exhaled hydrogen peroxide in stable COPD. Pulm Pharmacol Ther 2005; 18: 41-47.

17 Schleiss MB, Holz O, Behnke M, Richter K, Magnussen H, Jörres RA. The concentration of hydrogen peroxide in exhaled air depends on expiratory flow rate. Eur Respir J 2000; 16: 1115-1118.

18 Antczak A, Nowak D, Bialasiewicz P, Kasielski M. Hydrogen peroxide in expired air condensate correlates positively with early steps of peripheral neutrophil activation in asthmatic patients. Arch Immunol Ther Exp (Warsz) 1999; 47: 119-126.

19 Szkudlarek U, Maria L, Kasielski M, Kaucka S, Nowak D. Exhaled hydrogen peroxide correlates with the release of reactive oxygen species by blood phagocytes in healthy subjects. Respir Med 2003; 97: 718-725.

20 National Heart, Lung and Blood Institute/World Health Organization. Global strategy for the diagnosis, management, and prevention of chronic obstructive pulmonary disease. NHLBI/WHO Global Initiative for Chronic Obstructive Lung Disease (GOLD) Workshop summary. Am J Respir Crit Care Med 2001; 163: 1256-1276. For an update of definitions (2004) see www.goldcopd.com. Date last updated: September 2005. Date last accessed: February 28, 2006.

21 Quanjer PH, Tammeling GJ, Cotes JE, Pedersen OF, Peslin R, Yernault JC. Lung volumes and forced ventilatory flows. Report Working Party Standardization of Lung 
Function Tests, European Community for Steel and Coal. Official Statement of the European Respiratory Society. Eur Respir J 1993; 6: Suppl. 16, 5-40.

22 Recommendations for standardized procedures for the online and off-line measurement of exhaled lower respiratory nitric oxide and nasal nitric oxide in adults and children - 1999. Am J Respir Crit Care Med 1999; 160: 2104-2117.

23 Ichinose M, Sugiura H, Yamagata S, et al. Xanthine oxidase inhibition reduces reactive nitrogen species production in COPD airways. Eur Respir J 2003; 22: 457-461.

24 Latzin P, Griese M. Exhaled hydrogen peroxide, nitrite and nitric oxide in healthy children: decrease of hydrogen peroxide by atmospheric nitric oxide. Eur J Med Res 2002; 7: 353-358.

25 Domagala-Kulawik J, Guzman J, Costabel U. Immune cells in bronchoalveolar lavage in peripheral lung cancer analysis of 140 cases. Respiration 2003; 70: 43-48.

26 Beeh KM, Beier J, Ernst M, Kornmann O, Buhl R. Platinumbased, leukocyte-depleting chemotherapy does not alter induced sputum markers of neutrophilic inflammation in COPD patients with unresectable non-small cell lung cancer. Respiration 2003; 70: 166-171.

27 Hara N, Ichinose Y, Motohiro A, Kuda T, Aso H, Ohta M. Influence of chemotherapeutic agents on superoxide anion production by human polymorphonuclear leukocytes. Cancer 1990; 66: 684-688.
28 Somani S, Husain K, Whitworth C, Trammell G, Malafa M, Rybak L. Dose-dependent protection by lipoic acid against cisplatin-induced nephrotoxicity in rats: antioxidant defense system. Pharmacol Toxicol 2000; 86: 234-241.

29 Palma JP, Aggarwal SK. Cisplatin and carboplatin mediated release of cytolytic factors in murine peritoneal macrophages in vitro. Anticancer Drugs 1994; 5: 615-622.

30 Son K, Kim YM. In vivo cisplatin-exposed macrophages increase immunostimulant-induced nitric oxide synthesis for tumor cell killing. Cancer Res 1995; 55: 5524-5527.

31 Ranjan P, Sodhi A, Singh SM. Murine peritoneal macrophages treated with cisplatin and interferon-gamma undergo NO-mediated apoptosis via activation of an endonuclease. Anticancer Drugs 1998; 9: 333-341.

32 Högman M, Holmkvist $\mathrm{T}$, Walinder $\mathrm{R}$, et al. Increased nitric oxide elimination from the airways after smoking cessation. Clin Sci (Lond) 2002; 103: 15-19.

33 Hilbert J, Mohsenin V. Adaptation of lung antioxidants to cigarette smoking in humans. Chest 1996; 110: 916-920.

34 van Beurden WJ, Dekhuijzen PN, Harff GA, Smeenk FW. Variability of exhaled hydrogen peroxide in stable COPD patients and matched healthy controls. Respiration 2002; 69: 211-216.

35 Van Hoydonck PG, Wuyts WA, Vanaudenaerde BM, Schouten EG, Dupont LJ, Temme EH. Quantitative analysis of 8-isoprostane and hydrogen peroxide in exhaled breath condensate. Eur Respir J 2004; 23: 189-192. 